TITLE:

\title{
How the physical properties of food influence its selection by infant Japanese macaques inhabiting a snow-covered area.
}

\author{
AUTHOR(S): \\ Taniguchi, Haruka
}

CITATION:

Taniguchi, Haruka. How the physical properties of food influence its selection by infant Japanese macaques inhabiting a snow-covered area.. American journal of primatology 2014, 77(3): 285-295

ISSUE DATE:

2014-10-05

URL:

http://hdl.handle.net/2433/200313

\section{RIGHT:}

This is the peer reviewed version of the following article: Taniguchi, H. (2015), How the physical properties of food influence its selection by infant Japanese macaques inhabiting a snow-covered area. Am. J. Primatol., 77: 285-295., which has been published in final form at http://dx.doi.org/10.1002/ajp.22344. This article may be used for noncommercial purposes in accordance with Wiley Terms and Conditions for Self-Archiving.; This is not the published version. Please cite only the published version.; この論文は出版社版でありません。引用の際には出版社版をご磪認じ 利用ください。 
1 How the physical properties of food influence its selection by infant Japanese macaques inhabiting a snow-covered area

$6 \quad$ Haruka Taniguchi

8 Laboratory of Human Evolution Studies, Graduate School of Science, Kyoto

$9 \quad$ University, Kyoto, Japan

12 Infant Japanese macaque food selection

14 Corresponding author: Haruka Taniguchi

15 E-mail address: haruka@jinrui.zool.kyoto-u.ac.jp

16 Phone number: (+81) 075-753-4085 


\section{ABSTRACT}

19 Dietary differences exist between infant and adult female non-human primates.

20 These differences are considered to be related to the low ability of infants to bite,

21 handle, and obtain food items. This study aimed to provide a comprehensive 22 examination of how the physical properties of food items (fracture toughness, size, 23 processing, and height) influence food selection by infant primates. In this study, 4 24 mother-infant Japanese macaque (Macaca fuscata) pairs were investigated in a 25 snow-covered area during winter. The feeding behavior of both mothers and infants 26 was recorded. The size, need for processing, and height of food items were recorded 27 by direct observation, while the fracture toughness of food items (evaluating the required bite force by incisors) was measured using a rheometer. On average, infants spent $14 \%$ less time feeding than their mothers, and there were dietary differences between mothers and infants. Compared to their mothers, infants fed relatively more

31 frequently on food items that were small, at a low position, or that could be 32 consumed without processing. In addition, infants spent less time feeding on food 33 items that were tougher than $2000 \mathrm{~J} / \mathrm{m}^{2}$. Thus, infants fed relatively more frequently 34 on food items that are easy to obtain. This food selection by infants reduced the costs of feeding and allowed them to avoid falling from high trees. 


\section{INTRODUCTION}

Many studies of non-human primates indicate that food selection by mothers affects food selection by their infants [for review, see Rapaport \& Brown, 2008]. When infants start to eat solid foods, they copy the food selected by their mothers [Hikami et al., 1990; Jaeggi et al., 2010]. Yet, some studies have reported the presence of dietary differences between infants and adult females [Nakayama et al., 1999; Tarnaud, 2004], which are attributed to the physical [Altmann, 1980; Gunst et al., 2008; Gunst et al., 2010] and physiological [Nakayama et al., 1999] differences between the 2 age classes. Altmann [1980] observed that "weaning foods” are foods that are easily obtained and are eaten by infants during the transition from dependence on milk to full nutritional independence. Therefore, the physical properties of food items may partly influence food selection by infants during the period of weaning.

First, previous studies have shown that the toughness of food items influences food selection by infants. In long-tailed macaques (Macaca fascicularis), infants avoid eating fruits with hard rinds [van Schaik \& van Noordwijk, 1986]. A craniofacial biomechanical study in rhesus macaques (Macaca mulatta) showed that the mean incisor bite force of juveniles is half that of adults [Dechow \& Carlson, 2005]. Thus, the bite force in infants is considered to be much weaker than that of adults. In recent decades, several studies have used quantitative methods to examine how the toughness of food items influences food selection in primates [Hill \& Lucas, 1996; Kinzey \& Norconk, 1990]. These studies revealed a relationship between the ability to process food items and morphological features via interspecific and intraspecific comparisons [McGraw et al., 2011; Norconk \& Veres, 2011; Vogel et al., 
63 2008; Vogel et al., 2014, Wright et al., 2008]. However, previous studies have not

64 quantified the effect of food toughness on food selection by infants.

65 Second, the size of food items may affect food selection by infants. Infant 66 long-tailed macaques eat relatively smaller fruits than adults [van Schaik \& van 67 Noordwijk, 1986]. Since bite size can be a body-mass dependent trait of the masticatory apparatus, large-bodied animals generally feed on large food items more efficiently than small-bodied animals. On the other hand, small-bodied animals need to bite large food items many times [Nakagawa, 2008; Shipley et al., 1994; Wrangham et al., 1993].

Third, food items that need processing skill may affect food selection by infants. Several studies suggest that infants are less efficient foragers than juveniles and adults [Gunst et al., 2008; Gunst et al., 2010; Rhine \& Westlund, 1978; Stone, 2006]. For example, compared to juveniles and sub-adults, western lowland gorilla (Gorilla gorilla) infants tend to feed on food parts that are easier to obtain and that require no processing, because they lack the processing skills and physical strength (e.g., arm strength) necessary to access hard-to-process food items [Nowell \& Fletcher, 2008].

Fourth, another factor that might influence food selection by infants is the height at which food items are located. Before infants achieve full motor competence,

81 climbing and moving arboreally might increase the probability of fatal falls

82 [Chalmers, 1972; Dunbar \& Badam, 1998; Karssemeijer et al., 1990; Sussman, 1977].

83 In addition, compared to other age classes (particularly juveniles), rhesus macaque infants spend more time in low and stable positions [Wells \& Turnquist, 2001]. properties of food items, including toughness, size, processing, and height. However, 
previous studies only focused on a limited set of food items [Altmann, 1980; Gunst

et al., 2008; Gunst et al., 2010; Nowell \& Fletcher, 2008; Rhine \& Westlund, 1978] and on certain categories of food parts (e.g., fruits, leaves, and bark) [Nakayama et al., 1999; Tarnaud, 2004]. Few studies have considered all food items when examining the influence of the physical properties of food on dietary differences between infant and adult primates.

In temperate regions, it is important to survive in winter when the climate is harsh (i.e., cold and snow) and food availability is low [Nakagawa, 1997]. The Japanese macaque is the best-studied temperate primate, with its seasonal reproductive and foraging patterns being well-documented [Nakagawa et al., 2010]. Thus, this species presents an ideal model for studying age-related differences on revealing the feature of food selection by infants. Infant Japanese macaques (Macaca fuscata) are born in spring and need to eat solid foods before the onset of winter to meet their nutritional requirements, because the daily rate of milk transfer from mothers decreases by $50 \%$ at around 6 months of age [Tanaka, 1992]. Indeed, infant macaques start to increase solid food intake at 5-6 months of age [Iwamoto, 1982]. In snow-covered areas with cool-temperate deciduous forests, macaques are limited to bark and dormant buds as their main food items in winter [Suzuki, 1965]. Dietary differences between infant and adult female Japanese macaques have been previously reported. For instance,

106 infants primarily feed on buds in winter, whereas adult females mainly feed on bark

107 [Nakayama et al., 1999].

108 This study aimed to provide a comprehensive examination of the physical 109 properties that influence food selection by infant Japanese macaques. I hypothesize 110 that, compared to their mothers, infants feed more frequently on food items that are 
111 easily obtainable, because infant have a lower ability to bite, handle, and acquire

112 food items. Specifically, I hypothesize that, in comparison to their mothers, Japanese

113 macaque infants feed relatively more frequently on food items that (1) are softer; (2)

114 can be eaten in 1 bite; (3) do not need processing; and (4) are located at a lower

115 position in trees. In particular, it may be easy to validate the effect of the height of

116 food items in snow covered areas, because macaques tend to be limited to using food

117 items on trees (as ground vegetation is covered in snow) [Suzuki, 1965]. In addition,

118 a large number of studies have been conducted on the morphological development of

119 Japanese macaques, in terms of teeth and locomotor apparatus [Hamada, 1982;

120 Hamada, 1983; Ishida, 1972; Iwamoto, 1977; Iwamoto et al., 1984; Iwamoto, 1987].

121 Thus, the feeding pattern observed in the current study is discussed in relation to the morphological development of this species, to validate my hypotheses.

\section{METHODS}

125 This study complied with the research guidelines of the Primate Research Institute 126 of Kyoto University, Japan, and adhered to Japanese legal requirements. I also 127 adhered to the Principles for the Ethical Treatment of Nonhuman Primates delineated by the American Society of Primatologists.

\section{Study area and subjects}

131 The study was conducted in the southwestern part of the Shimokita Peninsula $132\left(41^{\circ} 30^{\prime} \mathrm{N}, 141^{\circ} 00^{\prime} \mathrm{E}\right)$ from December 27, 2008 to March 29, 2009. The forest located 133 at an altitude higher than $400 \mathrm{~m}$ above sea level (a.s.l.) is dominated by Fagus 134 crenata and Sasa species on the forest floor. In comparison, the forest located at an 
altitude below $400 \mathrm{~m}$ a.s.l. is a mosaic dominated by Thujopsis dolabrata and Quercus crispula. Approximately one-quarter of the forest is covered in plantations or secondary forests of Cryptomeria japonica, Pinus densiflora, Larix kaempferi, and Abies sachalinensis [Kanuma et al., 2000].

The daily mean temperatures during the study period were $1.1 \pm 2.6{ }^{\circ} \mathrm{C}$ (mean \pm SD, range $=-4.5-10.9^{\circ} \mathrm{C}$ ), and the daily mean minimum temperatures were $-2.2 \pm$ $2.2{ }^{\circ} \mathrm{C} \quad$ (range $=-7.3-6.7{ }^{\circ} \mathrm{C}$ ) (Japanese Meteorological Agency; http://www.jma.go.jp/jma/index.html; accessed 2013-10-31). The study area was covered in snow during this period; however, snow was sometimes absent in certain places (e.g., roads).

The study group was the A87 troop of Japanese macaques, comprising 51 individuals, including 13 adult females (estimated as being either over 7 years of age or parous) and 7 infants (less than 1 year of age). Four mother-infant pairs (Pairs ID1, ID2, ID3, and ID4) were investigated in this study. The ages of the infants ranged between 7 and 10 months during the study period. The focal infants consisted of 2 males and 2 females.

The focal mother-infant pairs were investigated by the focal animal sampling method [Altmann, 1974]. Either a mother or her infant was observed as the focal animal. Then, each animal was observed for 10 hours every 3 weeks. The total observation time for each animal was 40 hours during the study period. Each animal was continuously observed for 1 hour at a time. I changed focal animals each hour, unless no other subject individuals were within view of the observer.

The focal animal's activities (feeding, grooming, resting, traveling, and other), maternal carriage, and nipple contact were recorded by instantaneous sampling 
159 [Altmann, 1974] at 3-min intervals. In this study, I present data for infants relating to

160 the time spent in contact with the mother's nipple and carriage by the mother. The

161 definition of "feeding” included not only taking food items into the mouth, but also

162 processing (e.g., removal of a husk or digging an item out of the ground), and searching for (e.g., raking fallen leaves) food items by hand. When feeding was observed, I recorded the food item species, the food parts, the size of the food items, the need for processing, and the height at which feeding activity occurred. The food item parts were categorized as bark, dormant buds, leaves, seeds (including acorns and pinecones), roots (including rhizomes), twigs, and other. The size of food items was classified into 2 categories: (1) small: a food item entering an infant's mouth in 1 bite (less than approximately $1 \mathrm{~cm}$ in width), and (2) large: 2 or more bites required. The processing of food items was divided into 2 categories: (1) no processing required before a food item was taken into the mouth, and (2) processing required

172 before a food item was taken into the mouth. The average height of food items was 173 classified into 5 categories: (1) 0 m (i.e., on the ground), (2) 0-2 m, (3) 2-5 m, (4) 5$17410 \mathrm{~m}$, and (5) more than $10 \mathrm{~m}$.

\section{Measurement of fracture toughness}

177 Previous studies have found that forces at the molars are 2-2.5 times greater than 178 those at the incisors [Dechow \& Carlson, 2005]. Therefore, in this study, I limited the 179 measurement of fracture toughness to food items where macaques were observed to 180 use their incisors to make the initial bites. I measured the fracture toughness of the 32 181 food items that macaques fed on for more than $1.0 \%$ of total feeding time. I could not 182 collect or measure 3 food items (bark of Helwingia japonica, acorns of Q. crispula, 
Trametes spp.) among them. The bite force for bark, dormant buds, leaves, roots, and twigs was measured using a rheometer (COMPAC100II; SUN Scientific Co., Ltd. TM, Setagaya-ku, Tokyo, Japan). The rheometer measures a series of loads when a single blade cuts a food item. The load data were transferred to a computer using an analogue-digital converter (ADA16-32/2(CB)F, CONTEC Co., Ltd. ${ }^{\circ}$,

188 Nishiyodogawa-ku, Osaka, Japan). The load was measured every millisecond during the cutting process. The total workload was calculated as the integral of the series of loads. Before taking rheometer measurements, the cross-sectional area was measured using a digital caliper (CD-15PSX; Mitutoyo Corporation ${ }^{\circledR}$, Kawasaki-shi,

192 Kanagawa, Japan). The fracture toughness $\left(\mathrm{J} / \mathrm{m}^{2}\right)$ was determined using the total workload and cross-sectional area. The fracture toughness of each food item was measured more than 7 times, and the average of these measurements was used for analyses. The mechanical tests of food items were performed within 6 hours of collection. The fracture toughness was classified into 6 categories: (1) less than 500

$\mathrm{J} / \mathrm{m}^{2}$, and (6) more than $2500 \mathrm{~J} / \mathrm{m}^{2}$.

199 Food items for the measurement of fracture toughness were collected from 200 February 5 to 29, 2012. Bark was collected from the same twigs from which the 201 macaques ate bark. The bark was peeled off from the twig with the cambium layer 202 for the analysis. When I was unable to collect the twigs that the macaques fed on, I 203 collected the bark of similar twigs from the same tree. Dormant buds were measured 204 from the boundary between the bud and the twig. Leaves were measured from the 205 middle of the lamina without the midrib, because macaques sometimes did not feed 206 on the midrib. Roots were measured from the boundary between the leaves and roots. 
207 Rhizomes were measured at the mid-point between joints. Young twigs were

208 collected from the same tree from which a macaque fed on twigs. Macaques fed on

209 the top part of young twigs. I measured the position of the length $1 \mathrm{~cm}$ from the top

210 of young twigs, where macaques often fed. I could not always identify the species

211 name of ferns. The fracture toughness of ferns was based on the average fracture

212 toughness of Polystichum tripteron, on which macaques often fed.

213

\section{Relative feeding index}

215 For each mother-infant pair, the difference in time spent feeding on each food 216 item by the mother and its infant was calculated using the following formula 217 [Ichihara, 1990]:

$$
\text { Relative feeding index of food item } X=\frac{\left(P_{1}-P_{2}\right)-0}{\sqrt{P(1-P)\left(\frac{1}{n_{1}}+\frac{1}{n_{2}}\right)}}
$$

$219 \quad \mathrm{n}_{1}=$ Mother's total number of feeding sample points

$220 \quad \mathrm{n}_{2}=$ Infant's total number of feeding sample points

$n_{1 \text { food item } \mathrm{X}}=$ Mother's number of sample points feeding on food item $\mathrm{X}$

$n_{2}$ food item $\mathrm{X}=$ Infant's number of sample points feeding on food item $\mathrm{X}$

$\mathrm{P}_{1}=\frac{n_{1 \text { food item X }}}{n_{1}}, \mathrm{P}_{2}=\frac{n_{2 \text { food item X }}}{n_{2}}, \mathrm{P}=\frac{n_{1 \text { food item } \mathrm{X}}+n_{2 \text { food item } \mathrm{X}}}{n_{1}+n_{2}}$

224 A negative number indicates that an infant fed more on a given food item than its mother, whereas a positive number indicates the opposite. To remove the effect of 226 food items on which macaques fed less, the index of the food item where

$227 n_{1 \text { food item } \mathrm{x}}+n_{2 \text { food item } \mathrm{x}}$ was greater than 10 sample points was subject to 228 statistical analysis for each pair. 


\section{Statistical analysis}

To examine the influence of physical properties on the dietary difference between mothers and infants, I used a generalized linear mixed model (GLMM), assuming a normal distribution, with the relative feeding indices as a dependent variable, and 3 physical properties (size, processing, and height) as independent variables for each food item. I set the mother-infant pair ID as a random effect. Before using the GLMM, I checked whether the data set for the relative feeding index had a normal distribution using a Kolmogorov-Smirnov test. In addition, I calculated the variance inflation factors (VIF) among 3 factors (size, processing, and height) to check for multicollinearity. Montgomery and Peck [2001] suggest that if the VIF is over 5, the regression coefficients are poorly estimated. The VIF among the 3 factors was low enough for the analyses. Moreover, I added fracture toughness as an independent variable in the GLMM analysis for the measured food items. The normal distribution of the relative feeding indices was checked by the same method presented previously.

244 The VIF among the 4 factors (size, processing, height, and toughness) was low enough for the analyses.

All possible combinations of independent factors were examined, and model

247 fitness was assessed by the Akaike Information Criterion (AIC) [Burnham \& 248 Anderson, 2002]. I examined only the models that had a $\triangle$ AIC (difference from the 249 smallest AIC) of less than 2. To assess the relative likelihood of these models, I 250 calculated the Akaike weight as $\exp (-0.5 \times \Delta$ AIC score for that model $) /$ sum of $251 \exp (-0.5 \times \Delta$ AIC score $)$ for all of the models [Burnham \& Anderson, 2002]. I 252 presented the coefficient from the maximum-likelihood estimation in the best-fit 
model with the smallest AIC. In the physical properties selected for the best-fit model, the statistical difference was determined by the Mann-Whitney test or the Kruskal-Wallis test. For each pair, the dietary differences between the infant and its mother were analyzed using the $\chi^{2}$ test. Differences with a $P$ value of less than or equal to 0.05 with a two-tailed test were considered significant. I used the software program $\mathrm{R}$ 3.0.3 (The $\mathrm{R}$ Foundation for Statistical Computing; http://www.r-project.org/) for all statistical analyses.

\section{RESULTS}

\section{General description of feeding behavior}

During the study period, mothers and infants spent $44.8 \pm 6.3 \%(N=4$, range $=$ $40-54 \%)$ and $37.9 \pm 4.8 \%(N=4$, range $=32-44 \%)$ of time feeding on solid food items in total observation time, respectively. The infant/mother ratio for time spent feeding was $0.86 \pm 0.17(N=4$; range $=0.72-1.09)$. The time spent in contact with the mother's nipple was $21.3 \pm 5.6 \%(N=4$, range $=17-29 \%)$ and the time spent carriage by the mother was $0.41 \pm 0.24 \%(N=4$, range $=0.25-0.75 \%)$.

For all 4 mother-infant pairs, a dietary difference was present between the mother and its infant in terms of dietary composition of food items that were used in the calculation of relative feeding index (Table I; $\chi^{2}$ test: pair ID1, $\chi^{2}=193.76, P<0.01$, d.f. $=10$; pair ID2, $\chi^{2}=93.76, P<0.01$, d.f. $=12$; pair ID3, $\chi^{2}=112.88, P<0.01$, d.f. $=11$; pair ID4, $\chi^{2}=133.68, P<0.01$, d.f. $=15$ ). Table I shows the average time spent feeding on each food item by mothers and infants. Among the top 5 food items in terms of the time spent feeding, both mothers and infants contained leaves of Poaceae spp. and acorns of Q. crispula. The remaining 3 top food items differed 
between mothers and infants; infants contained buds of Sasa kurilensis, buds of

Zanthoxylum piperitum, and leaves of Carex spp., whereas mothers contained seeds of P. densiflora, bark of Actinidia arguta, and roots of Trifolium repens.

Relationship between the relative feeding index and 3 physical properties of food items

I examined the relationship between the relative feeding index and 3 physical properties of each food item (size, processing, and height). Fifty-two relative feeding indices $\left(N_{\text {pair ID1 }}=11 ; N_{\text {pair ID2 }}=13 ; N_{\text {pair ID3 }}=12 ; N_{\text {pair ID4 }}=16\right)$, including 23 different food items, were analyzed (Table I). For mothers, the percentage of time spent feeding on the food items used in this analysis to total feeding time was $79.0 \pm$ $2.8 \%(N=4$; range $=75-81 \%)$, whereas that for infants was $72.3 \pm 6.0 \%(N=4$; range $=69-81 \%$ ). The data set for the relative feeding index did not differ significantly from a normal distribution (Kolmogorov-Smirnov test, $D=0.13, N=$ 52, $P>0.1$ ). All 3 properties influenced the difference in time spent feeding by mothers and infants in the best-fit model. Compared to the mothers, infants fed more on food items that could be consumed in 1 bite, that required no processing, and that were located at a lower position (Tables IIa, IIIa and Fig. 1). Food item size and height were selected by the second fit model with a $\Delta$ AIC of less than 2 , and processing was not selected (Table IIa).

The size of the food item significantly affected the difference between mothers and infants (Tables IIIa). Food items that infants could eat with 1 bite mainly included buds (Fig. 1a). 
between infants and mothers, there was no significant difference between food items that did and did not require processing in the relative feeding indices (Tables IIa and IIIa). Food items that required processing contained roots and seeds, and the average relative feeding indices of 2 food items (Q. crispula acorns and P. lobata seeds) had negative numbers (Fig. 1b). For instance, the average relative feeding index of $Q$. crispula acorns (Table I; Food item No. 2) was $-1.04 \pm 2.31(N=4$; range $=-4.2-1.0)$. Infants did not tend to spend less time feeding on Q. crispula acorns, which required the cracking of the shells. In addition, the infants spent more time feeding on $P$. lobata seeds (No. 11), which required the shelling of pods ( $\chi^{2}$ test: pair ID1, $\chi^{2}=$ 21.58, $P<0.01$, d.f. $=1)$.

Finally, the height of the food item significantly affected the difference between mothers and infants (Tables IIIa). All average relative feeding indices of food items that were located at a height of more than $5 \mathrm{~m}$ were positive numbers (Fig. 1c), except for A. arguta buds (No. 9). Infants spent more time feeding on A. arguta buds ( $\chi^{2}$ test: pair ID4, $\chi^{2}=11.75, P<0.01$, d.f. $=1$ ). For the 23 food items (Table I), mothers and infants spent $24.9 \pm 4.1 \%(N=4$; range $=21-31 \%)$ and $7.9 \pm 3.3 \%(N=$ 4; range $=4.8-12 \%)$ time, respectively, feeding on food items that were located at a height of more than $5 \mathrm{~m}$ in the tree in total feeding time. For all 4 mother-infant pairs, infants spent significantly less time feeding on food items that were located at a height of more than $5 \mathrm{~m}$ than their mothers $\left(\chi^{2}\right.$ test: pair ID1, $\chi^{2}=34.59, P<0.01$, d.f. $=1$; pair ID2, $\chi^{2}=26.83, P<0.01$, d.f. $=1$; pair ID3, $\chi^{2}=19.46, P<0.01$, d.f. $=1$; pair ID4, $\chi^{2}=21.98, P<0.01$, d.f. $=1$ ). 
325

326

327

328

329

330

\section{food items}

To clarify the influence of fracture toughness on dietary differences between mothers and infants, I examined the relationship between the relative feeding index and 4 physical properties (fracture toughness, size, processing, and height) of the food items. Thirty-nine relative feeding indices were analyzed ( $N_{\text {pair ID1 }}=7 ; N_{\text {pair ID2 }}$ $=10 ; N_{\text {pair ID3 }}=9 ; N_{\text {pair ID4 }}=13$ ), including 19 different food items for which macaques were observed to use their incisors in taking the initial bites (Table I). For mothers, the percentage of time spent feeding on the food items used in this analysis to total feeding time was $57.5 \pm 8.1 \%$ ( $N=4$; range $=46-65 \%$ ), whereas that for infants was $50.1 \pm 13.1 \%(N=4$; range $=31-60 \%)$. This dataset contained only 1 of 4 food items that required processing. The dataset relating to the relative feeding index did not differ significantly from a normal distribution (Kolmogorov-Smirnov test, $D=0.15, N=39, P>0.1$ ). In the best-fit model (Tables IIb and IIIb), size, height, and processing affected the difference in the time spent feeding by mothers and infants, and each effect had the same tendency as the above analysis (Tables IIa and IIIa). Fracture toughness was not selected in the best-fit model (Table IIb). However, the second fit model with a $\triangle$ AIC of less than 2 contained fracture toughness.

Although fracture toughness did not cause a major difference in the selection of food between mothers and infants, all average relative feeding indices of the food items that were tougher than $2000 \mathrm{~J} / \mathrm{m}^{2}$ were positive numbers (Fig. 1d). Among the 32 food items for which fracture toughness was measured, all infants spent significantly less time feeding on food items that had a toughness of more than 2,000 $\mathrm{J} / \mathrm{m}^{2}$ (Fig. 2 ; $\chi^{2}$ test: pair ID1, $\chi^{2}=5.37, P<0.05$, d.f. $=1$; pair ID2, $\chi^{2}=30.87, P<$ 
3490.01 , d.f. $=1$; pair ID3, $\chi^{2}=35.01, P<0.01$, d.f. $=1$; pair ID4, $\chi^{2}=34.34, P<0.01$,

350 d.f. = 1). Food items that were tougher than $2000 \mathrm{~J} / \mathrm{m}^{2}$ included some bark, $Z$.

351 piperitum twigs, $S$. kurilensis leaves, and Miscanthus sinensis roots.

352

353

354

355

356

357

358

359

360

361

362

363

364

365

366

367

368

369

370

371

372

\section{DISCUSSION}

The results of this investigation were almost concordant with my hypothesis. In summary, compared with their mothers, Japanese macaque infants fed relatively more on food items that are small, that require no processing, or that are located at a lower position. In addition, infants spent less time feeding on food items with a toughness greater than $2,000 \mathrm{~J} / \mathrm{m}^{2}$.

\section{Feeding and suckling by infants}

Throughout the study period, Japanese macaque infants still spent as much as $21.3 \%$ of their time suckling, and the average time spent feeding was 0.86 times that observed in mothers. This result is almost consistent with the findings of a previous study. In winter, Japanese macaque infants inhabiting a snow-covered areas, spent approximately 30\% less time feeding than adult females [Nakayama et al., 1999]. Nakayama and others [1999] suggest that the estimated fuel reserves do not meet the cumulative energy deficit of infants and adult females during winter, and the energy deficit of infants might be met by consuming milk from their mothers. Thus, infants need to feed on solid food, in addition to spending more time suckling during winter.

\section{Relationship between food fracture toughness and food selection by infants} (Hypothesis 1) 
373 Although infants did not feed relatively more frequently on food items that were softer, they spent less time feeding on food items that were tougher than $2000 \mathrm{~J} / \mathrm{m}^{2}$ compared to their mothers. These quantitative results are consistent with those of previous studies of long-tailed macaques that were conducted using qualitative methods [van Schaik \& van Noordwijk, 1986]. The ability to process food is known to be linked with the morphology of different species or age-sex class [McGraw et al., 2011; Norconk \& Veres, 2011; Vogel et al., 2008; Vogel et al., 2014; Wright et al., 2008]. Deciduous dentition is complete at around 7.5 months of age in Japanese macaques, and the age of eruption of the permanent teeth is around 18 months [Iwamoto et al., 1984; Iwamoto, 1987]. Therefore, the infants observed during the present study period had completed deciduous dentition, but did not have permanent teeth. According to a craniofacial biomechanical study [Dechow \& Carlson, 2005], when juveniles reach complete deciduous dentition, but occlusion of the first permanent incisors has yet to occur, the mean forces of juvenile incisors are only half those of adults. Thus, differences in the fracture toughness ranges of food items selected by mothers and infants might be the result of differences in their morphological features.

\section{Relationship between food size and food selection by infants (Hypothesis 2)}

Infants fed relatively more frequently on food items that could be eaten in 1 bite compared to their mothers. Bite size (amount of food eaten with a single bite) constrains the feeding rate [Nakagawa, 2008, Shipley et al., 1994]. The bite size of 
time to process large food items than large animals [Nakagawa, 2008; Wrangham et

al., 1993]. For instance, the feeding rate on buds was greater than that on bark in 0 year olds and 1 year olds whereas there was no difference in the feeding rate of these 2 food parts by older Japanese macaque classes [Nakayama et al., 1999]. Infants may increase their feeding efficiency by selecting smaller food items.

Relationship between food processing and food selection by infants (Hypothesis

Infants tended to feed relatively more frequently on food items requiring no processing than their mothers. However, processing was not selected by the second fit model, with no significant difference between food items that did and did not require processing in the relative feeding index.

Food items that require processing included roots, which that need to be dug out, and pinecones, the scales of which need to be peeled off. It might be difficult for

411 infants to feed on food items that require high arm strength and/or bite force for processing. Juvenile chacma baboons (Papio hamadryas ursinus) are significantly less efficient foragers than adult baboons primarily for difficult-to-extract resources [Johnson \& Bock, 2004]. In addition, adult Japanese macaques carry and wash grass roots, while juveniles have rarely been observed to dig roots [Nakamichi et al., 1998].

416 Nakamichi and others [1998] discussed the possibility that it may be difficult for 417 juveniles to dig out roots. In brown capuchins (Cebus apella), infants do not have 418 adult levels of proficiency at ripping bamboo stalks to extract larvae, with infants 419 devoting more time than adults and juveniles to foraging on other food items (shoots, 420 pith, and non-embedded insects) that are easy to obtain [Gunst et al., 2008]. It has 
been suggested that foraging efficiency and time allocation are linked to parallel changes in body size and dentition [Gunst et al., 2008]. The results of this study are generally consistent with these preceding studies.

Yet, the average relative feeding indices of 2 food items (Q. crispula acorns and $P$. lobata seeds) had negative numbers. For both mothers and infants, Q. crispula acorns (No. 2) were among the top 5 food items, and infants tended not to spend less time on this food item than their mothers. In addition, infants fed more frequently on $P$. lobata (No. 11) seeds, which required the pods to be shelled. Out of the food items available in winter, acorns and seeds have higher energy or protein content compared to other food items (e.g., bark, leaves, and buds) [Nakagawa, 1989; Nakagawa, 1997]. In particular, primate infants have a higher requirement for protein compared to adults [Oftedal et al., 1991]. If infants are able to access energy- or protein-rich food items that need processing, infants may feed at the same time as their mothers or may feed on these items more frequently than their mothers. However, to confirm these hypotheses, I must conduct a more detailed examination of on the processing of food items, and the relationship between the physical properties and nutritional content of food items.

\section{Relationship between food height and food selection by infants (Hypothesis 4)}

Infants fed relatively more frequently on food items that were located at low positions than their mothers. Since infants were only carried for $0.41 \%$ of the time, infants had to climb trees by themselves to feed on solid foods in winter. In addition, Japanese macaque infants over 4 months of age tend to decrease their proximity to their mothers when feeding [Ueno, 2005]. Infant rhesus macaques also use the 
ground and low or horizontal arboreal settings more than adults and juveniles [Wells

\& Turnquist, 2001]. Wells and Turnquist [2001] noted that ontogenetic changes in morphology are closely paralleled by changes in locomotor behavior.

In studies on the growth of the locomotor apparatus of Japanese macaques, the most notable ontogenetic changes in the musculoskeletal system occur during the first year of life. There is a shift from the newborn pattern of the propulsive mass of the hind limb in yearlings [Hamada, 1982; Hamada, 1983] and the locomotor apparatus acquires approximately the pattern of adults when monkeys are around 2 years of age [Ishida, 1972]. As infants grow up, their upper limb muscles develop for forward propulsion, including pulling up the body when climbing, in addition to improving the control of the movement of segments at the shoulder, elbow, and wrist joints. In contrast, the necessity for finger extension and flexion with power decreases [Hamada, 1982; Hamada, 1983; Ishida, 1972]. Thus, it may be more difficult for infants to move in trees because their locomotor apparatus is shifted toward quadrupedalism.

460 Compared to their mothers, infants fed more frequently on food items located less than $5 \mathrm{~m}$ above the ground. Infants may avoid the risk of falling from a high position by selecting the lower positions as feeding sites. However, compared to their mothers, 463 infants fed more on $A$. arguta buds (No. 9), which are positioned more than $5 \mathrm{~m}$ high. 464 A. arguta is a woody liana that twines around itself and forms a stable foothold. Thus, 465 A. arguta may be more accessible to infants than other food items that are located at 466 a height of over $5 \mathrm{~m}$.

467 Incidentally, it has been reported that the time allocated to arboreal travelling was 468 longer for juveniles than adults [Hanya, 2003; Watanuki \& Nakayama, 1993]. 
469 Arboreal feeding is advantageous for juveniles when eating buds and fruits on terminal twigs, because increased body mass may restrict immediate access to terminal twig areas [Hanya, 2003; Watanuki \& Nakayama, 1993]. However, the results of this study indicate that smaller body mass may not be an advantage for 473 infants when moving to terminal twigs at heights of over $5 \mathrm{~m}$. In rhesus macaques, juveniles (12-18 months of age) spent more time in the arboreal environment than adults and infants [Wells \& Turnquist, 2001]. This difference in the behavior pattern of juveniles and adults may be explained by the inverse relationship between body size and joint mobility, because there is a rapid decline in passive joint mobility until an age of approximately 15 months [DeRousseau et al., 1983]. In addition, juveniles are able to move more freely than infants, which do not have fully developed locomotor apparatus [Dunbar \& Badam, 1998]. In comparison with mothers and juveniles, infants probably spend more time feeding on food items at lower positions 482 in the tree after decreasing maternal carriage.

The results of the current study were almost concordant with my hypothesis that infants feed more frequently on food items that are easily obtainable than their mothers, because of the lower ability of infants to bite, handle, and access food items. These preferences, which are associated with the physical abilities of infants, save the costs of time and energy required for feeding [Janson et al., 1993; Johnson \& Bock, 2004], and help infants to avoid falling from high trees. During the weaning period, infants may acquire information about available foods or foraging skills from their mothers [Tarnaud \& Yamagiwa, 2008], while they spend more time feeding on easily obtainable foods, termed “weaning foods.” 
493

494

495

496

\section{ACKNOWLEDGMENTS}

I thank the Shimokita Forest Office for the permission to conduct research on the Shimokita Peninsula. I am grateful to Prof. Juich Yamagiwa, Dr. Naofumi Nakagawa, and Dr. Eiji Inoue for their support and guidance during this research. I am indebted to Mr. Haruki Kinoshita and Ms. Kiku Kinoshita for use of a house during my field research and to Mr. Shiro Matsuoka, Ms. Atsuko Matsuoka, Ms. Naka Nakashima, and Ms. Kouko Hanayama for their help with my research life and safety checks. I also thank Ms. Yuri Nakayama and members of the Japanese Macaques' Field Station in Shimokita Peninsula for their help and support in the field. I am grateful to Prof. Hirosi Ihobe, Dr. Daisuke Shimizu, and Dr. Daisuke Koyabu for their support and guidance with the rheometer. I thank Mr. Shunkichi Hanamura, Dr. Yuji Iwata, Dr. Wataru Yano, Dr. Yoshihiro Nakashima, Dr. Elizabeth Nakajima, two reviewers and the editor of this journal, and members of the Laboratory of Human Evolution Studies, Kyoto University, for their advice and support. Finally, I gratefully acknowledge the A87 troop, my study troop, which endured my persistent observations. This study was financed in part by the Cooperative Research Program of the Primate Research Institute of Kyoto University, the grants to Excellent Graduate schools program of MEXT, Japan, grants for Global COE Program (A06) to Kyoto University from MEXT, Japan, a Grant-in-Aid for Scientific Research (B, No. 23370099) from JSPS to N. Nakagawa and a Grant-in-Aid for JSPS Fellows (No. 241479) to H. Taniguchi.

(1)


517

518

519

520

521

522

523

524

\section{REFERENCES}

Altmann J. 1974. Observational study of behavior: sampling methods. Behaviour 49:3-4.

Altmann J. 1980. Baboon mothers and infants. Chicago: University of Chicago Press. 242 p.

Burnham KP, Anderson DR. 2002. Model selection and multi-model inference: a practical information-theoretic approach. New York: Springer. 488 p.

Chalmers N. 1972. Comparative aspects of early infant development in some captive cercopithecines. In: Poirier F, editor. Primate socialization. New York: Random House. p 63-82.

Dechow PC, Carlson DS. 2005. Occlusal force and craniofacial biomechanics during growth in rhesus monkeys. American Journal of Physical Anthropology 83:219-237.

DeRousseau CJ, Rawlins RG, Denlinger JL. 1983. Aging in the musculoskeletal system of rhesus monkeys: I. Passive joint excursion. American Journal of Physical Anthropology 61:483-494.

Dunbar DC, Badam, G.L. 1998. Development of posture and locomotion in free-ranging primates. Neuroscience and Biobehavioral Reviews 22:541-546.

Gunst N, Boinski S, Fragaszy DM. 2008. Acquisition of foraging competence in wild brown capuchins (Cebus apella), with special reference to conspecifics’ foraging artefacts as an indirect social influence. Behaviour 145:195-229.

Gunst N, Leca JB, Boinski S, Fragaszy D. 2010. The ontogeny of handling hard-to-process food in wild brown capuchins (Cebus apella apella): evidence from foraging on the fruit of Maximiliana maripa. American Journal 
of Primatology 72:960-973.

Hamada Y. 1982. Longitudinal somatometrical study on the growth patterns of newborn Japanese monkeys. Primates 23:542-557.

Hamada Y. 1983. Growth of the locomotor apparatus of the Japanese macaque based on analysis of muscular weights and limb segments. Journal of Anthropological Society of Nippon 91:347-362.

Hanya G. 2003. Age differences in food intake and dietary selection of wild male Japanese macaques. Primates 44:333-339.

Hikami K, Hasegawa Y, Matsuzawa T. 1990. Social transmission of food preferences in Japanese monkeys (Macaca fuscata) after mere exposure or aversion training. Journal of Comparative Psychology 104:233.

Hill DA, Lucas PW. 1996. Toughness and fiber content of major leaf foods of Japanese macaques (Macaca fuscata yakui) in Yakushima. American Journal of Primatology 38:221-231.

Ichihara K. 1990. Statistics for bioscience-practical technique and theory. Tokyo: Nankodo. 378 p.

Ishida H. 1972. On the muscular composition of lower extremities of apes based on the relative weight. Journal of the Anthropological Society of Nippon $80: 125-142$.

Iwamoto M. 1977. A somatometrical study on the Japanese monkey of deciduous tooth period. Journal of the Anthropological Society of Nippon 85:281-291.

Iwamoto M. 1987. Eruption of permanent teeth in Japanese monkeys (Macaca fuscata). Primate Research 3:18-28.

Iwamoto M, Hamada Y, Watanabe T. 1984. Eruption of deciduous teeth in Japanese 
monkeys. Journal of the Anthropological Society of Nippon 92:273-279.

566

567

Iwamoto T. 1982. Food and nutritional condition of free ranging Japanese monkeys on Koshima Islet during winter. Primates 23:153-170.

Jaeggi AV, Dunkel LP, Van Noordwijk MA, et al. 2010. Social learning of diet and foraging skills by wild immature Bornean orangutans: implications for culture. American Journal of Primatology 72:62-71.

Janson CH, van Schaik CP, Pereira M, Fairbanks L. 1993. Ecological risk aversion in juvenile primates: slow and steady wins the race. In: Pereira ME, Fairbanks LA, editors. Juvenile primates: Life history, development, and behavior. Chicago: University of Chicago Press. p 57-74.

Johnson SE, Bock J. 2004. Trade-offs in skill acquisition and time allocation among juvenile chacma baboons. Human Nature 15:45-62.

Kanuma K, Matsuda K, Yajima T. 2000. Change of forest zone and local community in Shimokita Peninsula (in Japanese). In: Suzuki N, editor. Shimokita Peninsula in the end of 20 century. Tokyo: Japan Foundation Center. p 25-38.

Karssemeijer GJ, Vos DR, Van Hooff JA. 1990. The effect of some non-social factors on mother-infant contact in long-tailed macaques (Macaca fascicularis). Behaviour 113:273-291.

Kinzey WG, Norconk MA. 1990. Hardness as a basis of fruit choice in two sympatric primates. American Journal of Physical Anthropology 81:5-15.

McGraw WS, Vick AE, Daegling DJ. 2011. Sex and age differences in the diet and ingestive behaviors of sooty mangabeys (Cercocebus atys) in the Taï Forest, Ivory Coast. American Journal of Physical Anthropology 144:140-153.

Montgomery DC, Peck EA. 2001. Introduction to Linear Regression Analysis, Third 
589

590

591

592

593

594

595

596

597

598

599

600

601

602

603

604

605

606

607

608

609

610

611

612

Edition. New York: Wiley. 641p. Nakagawa N. 1989. Bioenergetics of Japanese monkeys (Macaca fuscata) on Kinkazan Island during winter. Primates 30:441-460.

Nakagawa N. 1997. Determinants of the dramatic seasonal changes in the intake of energy and protein by Japanese monkeys in a cool temperate forest. American Journal of Primatology 41:267-288.

Nakagawa N. 2008. The scaling of feeding rate in wild primates: a preliminary analysis. Mammal Study 33:157-162.

Nakagawa N, Nakamichi M, Sugiura H. 2010. The Japanese macaques. Tokyo: Springer. 402p.

Nakamichi M, Kato E, Kojima Y, Itoigawa N. 1998. Carrying and washing of grass roots by free-ranging Japanese macaques at Katsuyama. Folia Primatologica 69:35-40.

Nakayama Y, Matsuoka S, Watanuki Y. 1999. Feeding rates and energy deficits of juvenile and adult Japanese monkeys in a cool temperate area with snow coverage. Ecological Research 14:291-301.

Norconk MA, Veres M. 2011. Physical properties of fruit and seeds ingested by primate seed predators with emphasis on Sakis and Bearded Sakis. The Anatomical Record 294:2092-2111.

Nowell AA, Fletcher AW. 2008. The development of feeding behaviour in wild western lowland gorillas (Gorilla gorilla gorilla). Behaviour 145:171-193.

Oftedal OT, Whiten A, Southgate D, Soest PV. 1991. The nutritional consequences of foraging in primates: the relationship of nutrient intakes to nutrient requirements. Philosophical Transactions of the Royal Society of London. 
613

614

615

616

617

618

619

620

621

622

624

625

626

627

628

629

630

631

632

633

634

635

636

Series B: Biological Sciences 334:161-170.

Rapaport LG, Brown GR. 2008. Social influences on foraging behavior in young nonhuman primates: Learning what, where, and how to eat. Evolutionary Anthropology 17:189-201.

Rhine RJ, Westlund BJ. 1978. The Nature of a Primary Feeding Habit in Different Age-Sex Classes of Yellow Baboons (Papio cynocephalu). Folia Primatologica 30:64-79.

Shipley LA, Gross JE, Spalinger DE, Hobbs NT, Wunder BA. 1994. The scaling of intake rate in mammalian herbivores. American Naturalist 143:1055-1082.

Stone AI. 2006. Foraging ontogeny is not linked to delayed maturation in squirrel monkeys (Saimiri sciureus). Ethology 112:105-115.

Sussman RW. 1977. Socialization, social structure, and ecology of two sympatric species of Lemur. In: Chevalier-Skolnikoff S, Poirier FE, editors. Primate Bio-Social Development. New York: Garland. p 515-528.

Suzuki A. 1965. An ecological study of wild Japanese monkeys in snowy areas. Primates 6:31-72.

Tanaka I. 1992. Three phases of lactation in free-ranging Japanese macaques. Animal Behaviour 44:129-139.

Tarnaud L. 2004. Ontogeny of feeding behavior of Eulemur fulvus in the dry forest of Mayotte. International Journal of Primatology 25:803-824.

Tarnaud L, Yamagiwa J. 2008. Age dependent patterns of intensive observation on elders by free ranging juvenile Japanese macaques (Macaca fuscata yakui) within foraging context on Yakushima. American Journal of Primatology 70:1103-1113. 
637 Ueno A. 2005. Development of co-feeding behavior in young wild Japanese macaques (Macaca fuscata). Infant Behavior and Development 28:481-491.

van Schaik CP, van Noordwijk MA. 1986. The hidden costs of sociality: intra-group variation in feeding strategies in Sumatran long-tailed macaques (Macaca fascicularis). Behaviour 99:296-315.

Vogel ER, Van Woerden JT, Lucas PW, et al. 2008. Functional ecology and evolution of hominoid molar enamel thickness: Pan troglodytes schweinfurthii and Pongo pygmaeus wurmbii. Journal of Human Evolution 55:60-74.

645 Vogel ER, Zulfa A, Hardus M, et al. 2014. Food mechanical properties, feeding ecology, and the mandibular morphology of wild orangutans. Journal of Human Evolution 75: 110-124.

648 Watanuki Y, Nakayama Y. 1993. Age difference in activity pattern of Japanese monkeys: Effects of temperature, snow, and diet. Primates 34:419-430.

650 Wells JP, Turnquist JE. 2001. Ontogeny of locomotion in rhesus macaques (Macaca mulatta): II. Postural and locomotor behavior and habitat use in a free-ranging colony. American Journal of Physical Anthropology 115:80-94.

653 Wrangham R, Conklin N, Etot G, et al. 1993. The value of figs to chimpanzees. International Journal of Primatology 14:243-256.

655 Wright B, Ulibarri L, O’Brien J, et al. 2008. It’s tough out there: variation in the toughness of ingested leaves and feeding behavior among four Colobinae in Vietnam. International Journal of Primatology 29:1455-1466. 
TABLE I. Percentage of time spent feeding by infants and mothers, the relative feeding index, and the physical properties of food items. Percentage of time spent feeding on food items was averaged for 4 focal infants and 4 focal mothers. The food items were arranged according to the time that infants spent feeding on them. The relative feeding index of the food item was averaged among mother-infant pairs that were used in the calculation of the relative feeding index.

\begin{tabular}{|c|c|c|c|c|c|c|c|c|c|c|c|c|}
\hline \multirow[b]{2}{*}{$\begin{array}{l}\text { Food } \\
\text { item } \\
\text { No. }\end{array}$} & \multirow[b]{2}{*}{$\begin{array}{l}\text { Food item } \\
\text { species name }\end{array}$} & \multirow[b]{2}{*}{ Food part } & \multicolumn{4}{|c|}{ Percentage of time spent feeding } & \multicolumn{2}{|c|}{ Relative feeding index } & \multicolumn{4}{|c|}{ Physical properties of the food item } \\
\hline & & & Infant & $※$ & Mother & $※$ & & $\begin{array}{c}※ ※ \\
\text { (Pair ID name) }\end{array}$ & Size & Processing & Height & $\begin{array}{c}\text { ※※ } \\
\text { Toughness }\end{array}$ \\
\hline 1 & Poaceae spp. & Leaf & 23.1 & 1 & 24.7 & 1 & 0.43 & 4 (All) & 2 & 1 & 1 & 2 \\
\hline 2 & Quercus crispula & Seed (Acorn) & 12.0 & 2 & $\underline{9.1}$ & 3 & -1.04 & 4 (All) & 2 & 2 & 1 & - \\
\hline 3 & Sasa kurilensis & Bud & $\overline{8.2}$ & 3 & $\overline{1.9}$ & & -3.69 & 4 (All) & 1 & 1 & 1 & - \\
\hline 4 & Zanthoxylum piperitum & Bud & 8.2 & 3 & 2.3 & & -3.47 & 4 (All) & 1 & 1 & 2 & 2 \\
\hline 5 & Carex spp. & Leaf & $\underline{5.1}$ & 5 & 3.6 & & -1.05 & 3 (ID1, 3, 4) & 2 & 1 & 1 & 3 \\
\hline 6 & Fraxinus lanuginosa & Bud & 2.8 & & 1.9 & & -0.97 & 4 (All) & 1 & 1 & 3 & 3 \\
\hline 7 & Viburnum dilatatum & Bud & 2.3 & & 1.2 & & -1.40 & 2 (ID2, 3) & 1 & 1 & 2 & 3 \\
\hline 8 & Celastrus orbiculatus & Bud & 2.0 & & 2.1 & & 1.52 & 2 (ID2, 4) & 1 & 1 & 4 & 2 \\
\hline 9 & Actinidia arguta & Bud & 2.0 & & 0.1 & & -3.51 & 1 (ID4) & 1 & 1 & 4 & 2 \\
\hline 10 & Fern & Leaf & 1.7 & & 0.7 & & -1.38 & 1 (ID2) & 2 & 1 & 1 & 2 \\
\hline 11 & Pueraria lobata & Seed & 1.6 & & 0 & & -4.76 & 1 (ID1) & 1 & 2 & 3 & - \\
\hline 12 & Actinidia arguta & Bark & 1.6 & & $\underline{7.5}$ & 4 & 4.37 & 3 (ID2, 3, 4) & 2 & 1 & 4 & 5 \\
\hline 13 & Actinidia polygama & Bud & 1.5 & & 0.4 & & -2.42 & 1 (ID4) & 1 & 1 & 3 & 1 \\
\hline 14 & Trifolium repens & Root (Rhizome) & 1.3 & & $\underline{5.5}$ & 5 & 3.22 & 3 (ID1, 3, 4) & 2 & 2 & 1 & 4 \\
\hline 15 & Euonymus oxyphyllus & Bark & 1.1 & & $\overline{1.2}$ & & -0.21 & $2(\mathrm{ID} 2,4)$ & 2 & 1 & 3 & 4 \\
\hline 16 & Evodiopanax innovans & Bud & 1.0 & & 1.2 & & -1.67 & 1 (ID1) & 1 & 1 & 3 & 2 \\
\hline 17 & Pinus densiflora & Seed ( Pinecone) & 0.7 & & $\underline{10.4}$ & 2 & 5.10 & 4 (All) & 1 & 2 & 5 & - \\
\hline
\end{tabular}




\begin{tabular}{|c|c|c|c|c|c|c|c|c|c|c|}
\hline 18 & Hydrangea petiolaris & Bud & 0.7 & 1.9 & 1.08 & 2 (ID1, 3) & 1 & 1 & 4 & 2 \\
\hline 19 & Fraxinus lanuginosa & Bark & 0.7 & 2.6 & 2.31 & 2 (ID2, 4) & 2 & 1 & 3 & 6 \\
\hline 20 & Zanthoxylum ailanthoides & Bark & 0.7 & 1.5 & 3.21 & 1 (ID3) & 2 & 1 & 4 & 3 \\
\hline 21 & Euonymus oxyphyllus & Bud & 0.7 & 1.5 & 3.28 & 1 (ID4) & 1 & 1 & 3 & 2 \\
\hline 22 & Actinidia polygama & Bark & 0.7 & 1.5 & 3.83 & 1 (ID2) & 2 & 1 & 3 & 5 \\
\hline 23 & Celastrus orbiculatus & Bark & 0.2 & 1.4 & 2.84 & 1 (ID4) & 2 & 1 & 4 & 6 \\
\hline
\end{tabular}

$※$ Ranking in the time spent feeding for the top five underlined food items.

$※ \times$ Number of mother-infant pairs used in the calculation of the relative feeding index

$※ ※ ※$ “”” indicates that I did not measure the fracture toughness of the food item 
TABLE II. Summary of the generalized linear mixed models for the effect of physical properties on the relative feeding index.

\begin{tabular}{|c|c|c|c|}
\hline Adopted factor & AIC & $\triangle \mathrm{AIC}$ & Akaike weight (\%) \\
\hline \multicolumn{4}{|c|}{ (a) 52 relative feeding indices involving 23 different food items } \\
\hline Size +, Height + , Processing + & 249.5 & 0 & 72 \\
\hline Size + , Height + & 251.4 & 1.88 & 28 \\
\hline \multicolumn{4}{|c|}{ (b) 39 relative feeding indices involving 19 different food items, including toughness as the independent variable } \\
\hline Size + , Height + , Processing + & 185.3 & 0 & 59 \\
\hline Size + , Height + , Processing + , Toughness + & 187.3 & 1.97 & 22 \\
\hline
\end{tabular}

$\triangle A I C$ is the difference with the smallest Akaike information criterion (AIC). Akaike weight: $\exp (-0.5 \times \triangle \mathrm{AIC}) / \Sigma \exp (0.5 \times \triangle \mathrm{AIC})$

[Burnham \& Anderson, 2002].

“_” denotes a negative correlation between the relative feeding index and the physical property, while “+” denotes a positive correlation between them. A positive number for the relative feeding index indicates that infants fed less than their mothers did on a food item. 
TABLE III. Best-fit generalized linear mixed model for the effect of physical properties on the relative feeding index.

\begin{tabular}{|c|c|c|c|c|c|}
\hline Adopted factors & Partial regression coefficient & SE & Statistical test & Test statistic & $P$ \\
\hline \multicolumn{6}{|c|}{ (a) 52 relative feeding indices involving 23 different food items } \\
\hline Size & 3.25 & 0.71 & $\begin{array}{l}\text { Mann-Whitney test } \\
\left(N_{1}=27 ; N_{2}=25\right)\end{array}$ & $z=2.04$ & $<0.05$ \\
\hline Processing & 1.58 & 0.79 & $\begin{array}{l}\text { Mann-Whitney test } \\
\left(N_{1}=40 ; N_{2}=12\right)\end{array}$ & $z=1.67$ & 0.09 \\
\hline Height & 1.57 & 0.26 & $\begin{array}{l}\text { Kruskal-Wallis test } \\
\left(N_{1}=19 ; N_{2}=6 ; N_{3}=13 ; N_{4}=10 ; N_{5}=4\right)\end{array}$ & $\begin{array}{l}\chi^{2}=16.7 \\
\text { d.f. }=4\end{array}$ & $<0.01$ \\
\hline \multicolumn{6}{|c|}{ (b) 39 relative feeding indices involving 19 different food items, including toughness as the independent variable } \\
\hline Size & 3.21 & 0.77 & $\begin{array}{l}\text { Mann-Whitney test } \\
\left(N_{1}=18 ; N_{2}=21\right)\end{array}$ & $z=2.62$ & $<0.01$ \\
\hline Processing & 3.78 & 1.47 & $\begin{array}{l}\text { Mann-Whitney test } \\
\left(N_{1}=36 ; N_{2}=3\right)\end{array}$ & $z=1.42$ & 0.15 \\
\hline Height & 1.38 & 0.35 & $\begin{array}{l}\text { Kruskal-Wallis test } \\
\left(N_{1}=11 ; N_{2}=6 ; N_{3}=12 ; N_{4}=10\right)\end{array}$ & $\begin{array}{l}\chi^{2}=9.2 \\
\text { d.f. }=3\end{array}$ & $<0.05$ \\
\hline
\end{tabular}

The coefficient is from maximum-likelihood estimation. SE is the standard error of the coefficient. 


\section{Figure Legends}

Fig. 1. Relationship between the relative feeding index and physical properties.

A negative number indicates that infants fed more than their mothers did on a food item, while a positive number indicates that infants fed less than their mothers did on a food item. The means of each food item in Table I are plotted. The number on the right side of the plot represents the food item number in Table I.

(a) Size: Food item size was classified into 2 categories: (1) small: eaten by infants in 1 bite, and (2) large: eaten by infants in two or more bites.

(b) Processing: The need for processing food items was divided into 2 categories: (1) no processing required before a food item was taken into the mouth, and (2) processing required before a food item was taken into the mouth.

(c) Height: The average height of food items where feeding was observed was classified into 5 categories: (1) 0 m (i.e., on the ground), (2) 0-2 m, (3) 2-5 m, (4) 5$10 \mathrm{~m}$, and (5) more than $10 \mathrm{~m}$.

(d) Fracture Toughness: The average fracture toughness of the food items was classified into 6 categories: (1) less than $500 \mathrm{~J} / \mathrm{m}^{2}$, (2) 500-1000 J/m², (3) 1000-1500

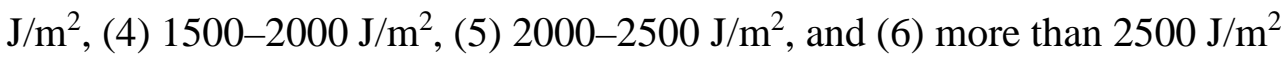

Fig. 2. Relationship between fracture toughness and the percentage of time spent feeding.

The fracture toughness of 32 food items that the macaques were observed to use their incisors to make the initial bites was measured. 
(a)

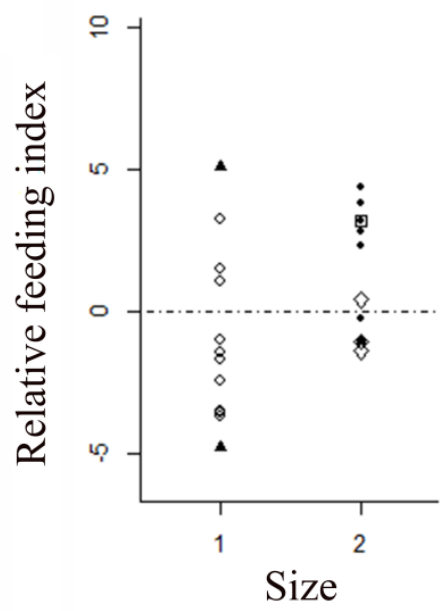

(c)

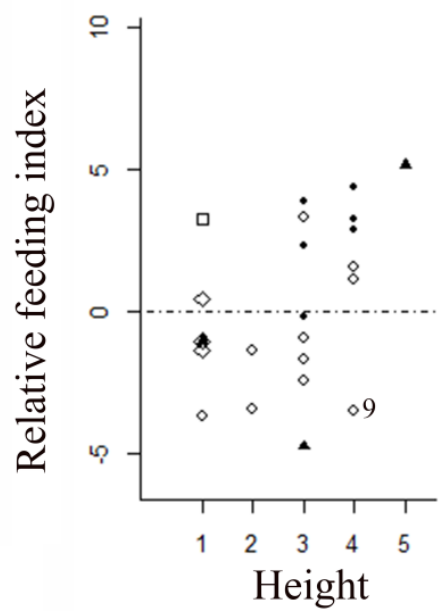

(b)

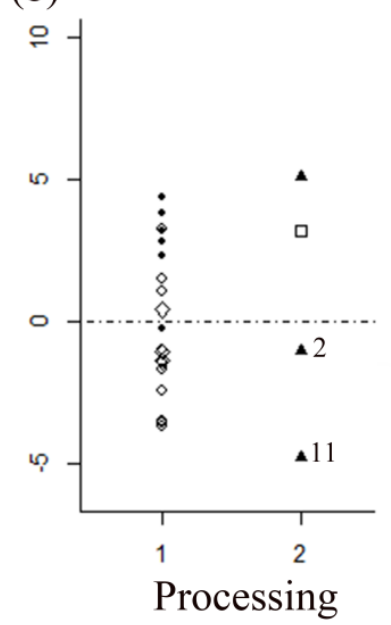

(d)

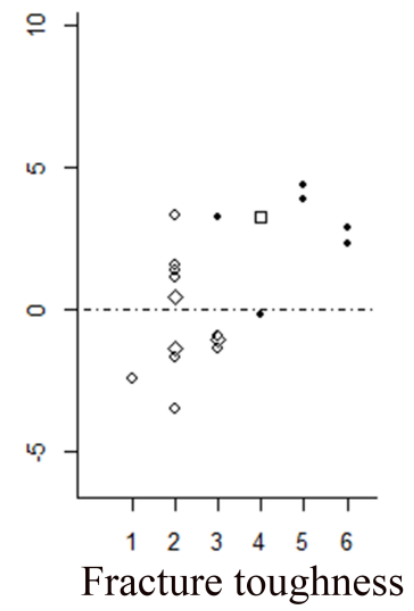

- Bark $\circ$ Bud $\diamond$ Leaf $\square$ Root $\wedge$ Seed

Fig. 1. Relationship between the relative feeding index and physical properties. 
Taniguchi 35

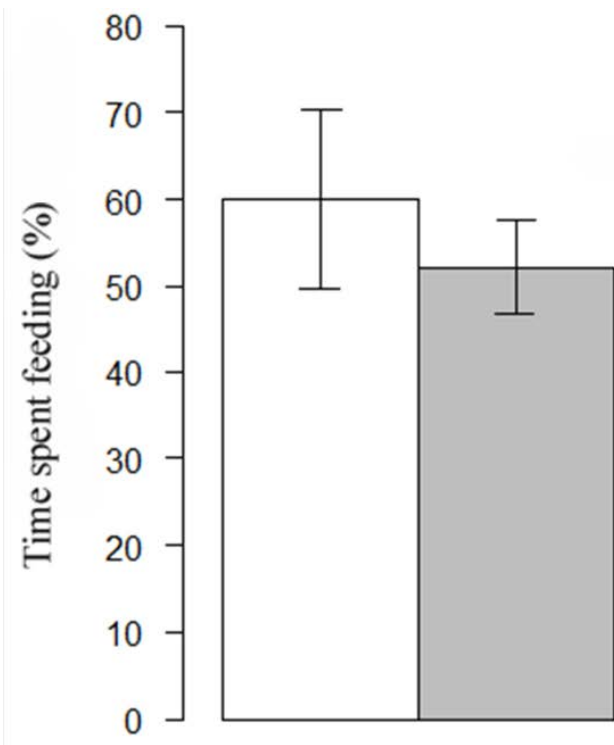

less than $2000 \mathrm{~J} / \mathrm{m}^{2}$ $\square$ Infant

Mother

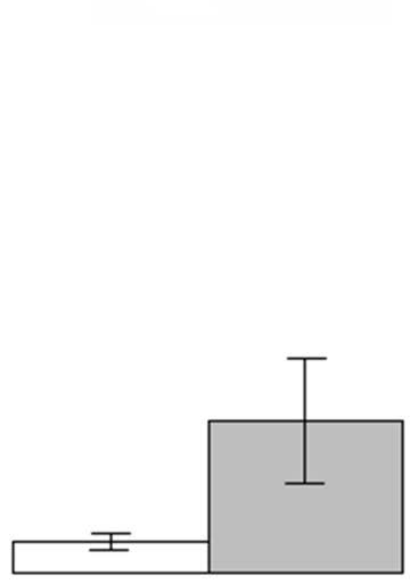

more than $2000 \mathrm{~J} / \mathrm{m}^{2}$

Fig.2. Relationship between fracture toughness and the percentage of time spent feeding. 